And all that may be said goes to show that convulsion or spasm has nothing to do with inflammation or active determination of blood, or congestion or fever. Epilepsy is often suspended for a time by the patient having been severely buraed during a fit. It seems as if there was something in the inflammation and fever set up by the burn which is uncongenial to the fit; nay, it must be so, for, as a rule, fits which happened frequently before the burn keep away until the process of healing is complete and the circulation has returned to its natural condition, which is always somewhat under the mark as to activity. Nor can spasm be looked upon as the characteristic symptom of acute spinal meningitis. It is, indeed, quite a mistake to look upon spasm as being thus characteristic, for when the history of this disorder is carefully looked into it is found (I am speaking now of the disorder when inflammation is actually developed) that the so-called spasm is little or no more than a voluntary or semi-voluntary fixing of the spinal column, of which the object is to prevent the very severe pain caused by moving the exquisitely tender spinal cord. Only let the patient keep quite still, and he is little likely to have much pain, or any symptom which may be looked upon as spasmodic. I can appeal to evidence in support of this statement, but not here. Indeed, here, for want of space, all $I$ can do is to say that it is so, not only in the convulsion or spasm about which I have been speaking, but also in any analogous phenomenon, physiological or pathological, and that much is said in "Vital Motion as a mode of Physical Motion" to make good this statement. Indeed, instead of having to do with the vital property of irritability as the master-key to life as manifested in muscle and motor nerve, I have only to do with electricity. And I am, I think, not the loser in adopting this course. I am not the loser as regards the vital property of irritability, for this property is no more than an occult property akin to the virtus dormitivo of opium. Now, the vital property of irritability which is looked upon as the cause of life in nerve and muscle is of the same parentage as the virtus dormitiva of opium, about which Molière makes fun. ${ }^{6}$ It is equally an occult quality. It is equally an empty dream of the schoolmen of the middle ages, which has no foundation in fact, and about which the wonder is that it should have outlived the virtus dormitiva so verylong. Indeed, do what I may, I cannot account for this anomalous state of things in these days when the reign of facts is supreme. And I am not the loser so far as the electrical hypothesis is concerned, for, by falling back upon charge and discharge, and supposing that the charge brings about relaxation by keeping the muscular molecules in a state of mutual repulsion, and that the discharge brings about contraction by allowing the attractive force which is adherent in the physical constitution of the molecules to come into play, I pass at once from the unknown and unknowable to the known, from mysterious metaphysics to plain physics, from the realm of fancy into that of fact. Indeed, so far from being the loser by adopting this view, I am, as I take it, in every way the gainer.

\section{HYPERTROPHY AND ITS COUNTERFEITS.}

BY J. BLAND SUTTON, F.R.C.S.,

HUNTERIAN PROFESSOR, ROYAL COLLEGE OF SURGEONS; ABSISTANTSURGEON, MIDDLESEX HOSPITAX.

$$
\text { (Concluded from page 13.) }
$$

BEFORE dismissing overgrowth, we ought to consider a variety of the process which is difficult to define, but is better illustrated by an example. The roach represented in Fig. 5 presents a large tumour growing from its side. The scales covering the tumour are in many places more than three times larger than those on the healthy parts of the fish; in the sketch a normal and abnormal scale are drawn of natural sizes for comparison. Notwithstanding the great difference in the sizes of the scales, the amount of material in each is equal. As the tumour increased in size the matrix of the scales expanded and produced scales of extreme tenuity. The specimen is preserved in the museum of the Royal College of Surgeons. A somewhat similar condition may be studied occasionally in man, in connexion with the subungual exostosis. As the exostosis grows it expands the matrix of the nail, and the

6 Molière: La Malade Imaginaire, 3ieme intermède. surface of the neoplasm becomes covered with a corneous cap. This expansion of the nail matrix is not constant. The same applies to the enormously distended skull in hydrocephalus. In these crania the cubic capacity may exceed the normal some two or three times, yet the total amount of osseous material in these skulls is often less than in a healthy skull of corresponding age. These specimens illustrate clearly enough that enlargements of this character should not be confounded with hypertrophy.

Fig. 5.

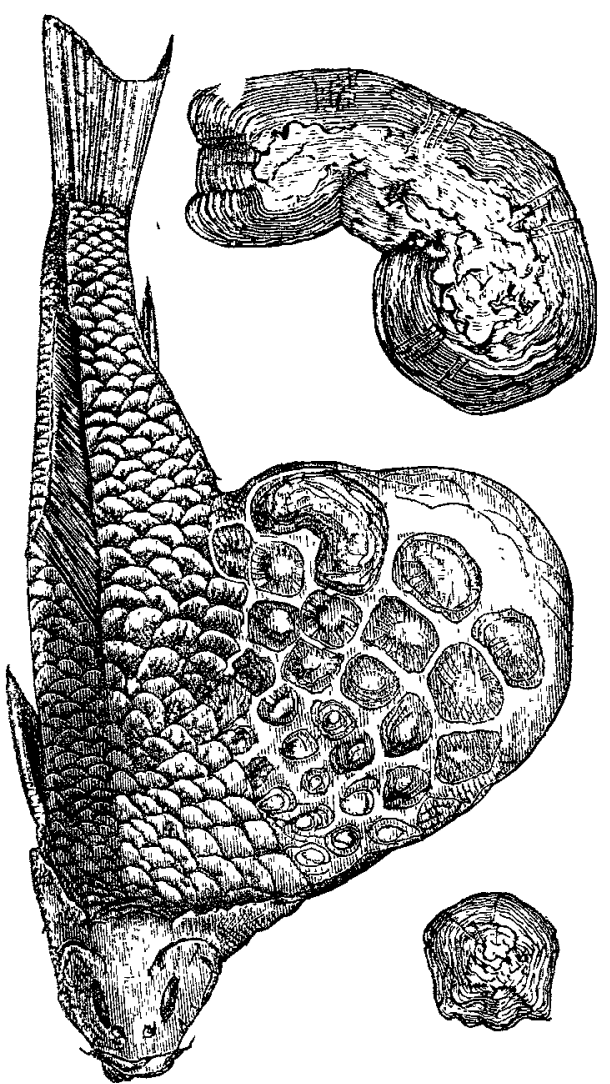

A roach with a spindle-celled sarcoma growing from its side. The lower figure represents the natural size of the scales over the tumour.

The following case, communicated to me by Mr. R. E. Holding, is interesting as illustrating the disastrous effects of overgrowths. The horns of a Norfolk ox had grown unduly, and become so displaced that they crossed each other beneath the mouth in such a manner that the jaws

F'IG, 6.

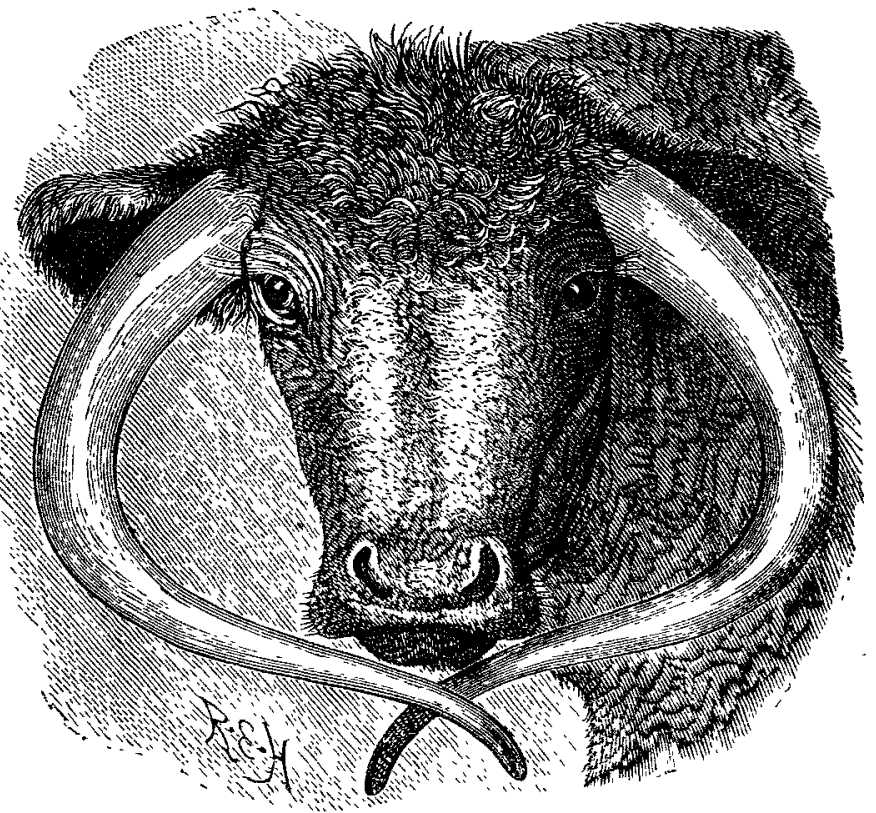

Abnormal position and overgrowth of the horns of a Yorfolk ox.

could only be opened for a distance of two inches. The animal could only feed itself with difficulty. It was fattened for the butcher by having its food administered by an attendant. The position of the horns is well shown in the accompanying engraving. (Fig. 6.) The constant 
rubbing of the jaws on the horn had produced two bald patches on the skin.

3 Inflammatory enlargement.-The distinctions between hypertrophy and increased size the result of inflammation, acute or chronic, are so obvious that it is difficult to understand how the two conditions can be misinterpreted; yet it is so. We hear of the hypertrophic form of cirrhosis, hypertrophous emphysema, hypertrophy of the prostate; even bones thickened from periostitis and ostitis deformans are described as examples of hypertrophy. Such loose method in the application of terms should be sedulously avoided; it is productive of error. The consideration of the specimens described in this paper ought to be sufficient to convince anyone that hypertrophy, overgrowth, and inflammatory enlargement are in no sense identical. Hypertrophy is a very salutary process, and in many instances is essential for the preservation of life. Overgrowth is at its best an inconvenience, and often disastrous; the same applies to inflammatory enlargement. In another place I have discussed the important part played by hypertrophy in evolution and have in consequence avoided it here.

In concluding this paper it may be of some interest to draw attention to a few points connected with overgrowth of hair. The skin of all mammals is furnished with hair or its modifications; the amount of hair may be very small in such forms as the whale, porpoise, elephant, and man. Few mammals have less hair than man, and in no member of man's class (mammalia) has hair a similar distribution. Even the quadrumana, which anatomically and zoologically approach man so closely, in the distribution and amount of hair differ from him very widely. In the apes, if deficiency occurs anywhere, it is on the ventral aspect; in man the reverse of this pertains, for the back is as a rule naked. It is scarcely correct, however, to make this statement emphatically, for the skin is in most parts of the body usually covered by a crop of thin downy hairs, which in such situations as the tip of the nose may be of excessive tenuity. In exceptional cases the hair on the general surface of the body may attain a considerable length and thickness; in rarer instances it may even be furnished with an aftershaft, an event very common with feathers. Hairy men such as Esau are not uncommon. It is well known that when the skin is persistently irritated, as by the application of poultices, the hairs in the neighbourhood may grow actively, and attain an abnormal length. All forms of local hairiness induced in this way must be regarded as overgrowth, the result of increased blood supply to the part in consequence of irritation. This is very well shown in the abnormal growth of hair occasionally seen on the forearm in some cases of arterio-venous aneurysm. Perhaps the most remarkable form of hairiness is that accompanying some cases of spina bifida occulta, and is probably due, as Virchow believes, to irritation of the spinal nerves in the region of the defect. In patients with a hidden spina bifida it is not uncommon, but by no means constant, to find a hair-field in the loins, the individual hairs of which may be very long; the abnormal growth may affect a very limited area. At other times the overgrowth is distributed over a very wide area, extending from the loins to the buttocks and down the thighs. In this variety the hairs are much shorter than in the firstmentioned condition. Persons with this form of spina bifida are not infrequently the subject of perforating ulcer on one or both feet.

In October, 1884, Virchow communicated to the Berliner medicinischen Gessellschaft a paper of very great interest on "Schwanzbildung beim Menschen," wherein he drew attention briefly to the statues and mythological narratives representing the satyrs and "gods of the woods," with tufts of hair for tails. Virchow suggests that the sculptors and artists did not trust entirely to their own imaginations, but that these oddities had a certain amount of foundation in fact. There is much to support this view of the matter, and I was induced to look into it. The sylvan deities consist of two varieties, Fauns and Aggipans. In fauns we find sprouting from the loins a hairy tuft. In the case of the ægipans, we have always the body of a man with longpointed ears, attached to the hind quarters of a goat, and a long tuft of hair in the loin. The combination is well represented in Fig. 7, showing an ægipan supporting a faun on its foot. The hairy tuft needs no further explanation, and the notion of hairy legs may have originated from those cases in which remarkable hair fields occasionally exist on the limbs, as complications of the spina bifida occulta. The notion of the cloven hoof admits of a twofold explanation In the first place, the distortion of the foot in the position of talipes equino-varus may have stimulated the imagination; or, in the second place, as Recklinghausen suggests, that, as the condition is so frequently complicated by perforating ulcer, and this disease leads to destruction of the metatarsal bones and loss of a few toes, a fancied

FIG. 7.



An ægipan supporting a faun.

resemblance to a cloven hoof originated. Nor is this merely supposition, for I have seen the second, third, and fourth toes thus destroyed, the big and little toes alone remaining, the first having a very suggestive cloven appearance. In conclusion, it is not unfair to infer that from such sources as these originated the familiar corporeal form of our muchdreaded mystical devil, with hairy body, cloven feet, and tail.

\section{THE PATHOLOGY OF INFECTIOUS AND INFECTIVE DISEASES,}

AS ILLUSTRATED BY THE FACTS OF INHERITANCF.

$$
\begin{gathered}
\text { BY JOSEPH COATS, M.D. } \\
\text { (Continued from p. 11.) }
\end{gathered}
$$

I HAVE adduced the foregoing examples of inheritance of morbid conditions somewhat in detail, in order to supply a basis for my further observations. I apprehend that theses instances in the first place afford demonstration of the fact of inheritance, while in the second place they indicate that the matter of inheritance consists in more or less minute structural or physiological details. It is a peculiarity in the formation of the epidermis, as in ichthyosis ; or in the structure of the bloodvessels, as in hæmophilia; or in the structure of the retina, as in Daltonism; or in the innervation of the muscles of the eye, as in squinting; or in the condition of the blood and kidneys, perhaps dependent on the condition of certain nerve centres, as in diabetes inspidus. Just as in the case of inheritance of normal characteristics, so here in morbid peculiarities, the fertilised ovum begins its career with specific forces, certain of which result in divergences from the normal.

\section{INHERITANCE OF INFECTIOUS AND INFECTIVE DISEASES.}

And now in approaching, after this long introduction, the subject which forms more particularly our theme, we may expect to find that if inheritance plays any part in infective and infectious diseases, it must do so on principles consistent with those which I have adduced.

The first observation I have to make is that race plays a very important part in the etiology of this class of cases. 